\title{
Hydrogen Diffusivity and Electrolyte Permeability of the Zirfon PERL Separator for Alkaline Water Electrolysis
}

\author{
Maximilian Schalenbach, ${ }^{\mathrm{a}, \mathrm{c}, \mathrm{z}}$ Wiebke Lueke, ${ }^{\mathrm{a}}$ and Detlef Stolten ${ }^{\mathrm{a}, \mathrm{b}}$ \\ ${ }^{a}$ Electrochemical Process Engineering (IEK-3), Forschungszentrum Jülich GmbH, 52425 Jülich, Germany \\ ${ }^{b}$ Chair for Fuel Cells, RWTH Aachen University, Aachen 52062, Germany
}

\begin{abstract}
The hydrogen and oxygen evolved during alkaline water electrolysis with liquid $\mathrm{KOH}$ electrolytes are typically separated using porous separators such as Zirfon PERL (Agfa), a commercially available composite of zirconium oxide and polysulfone. In this study, the hydrogen diffusivity (driven by concentration differences) and electrolyte permeability (driven by differential pressures) of the Zirfon PERL separator were characterized as a function of the temperature and molarity of the KOH filling. The diffusivity of hydrogen in the separator was found to be approximately $16 \%$ of that of the electrolyte filling inside its pores. With respect to water electrolysis conditions, the extent of hydrogen cross-permeation caused by the convection of the cross-permeating electrolyte was estimated and compared to that caused by diffusion. On the basis of the physically characterized mechanisms, smaller pores were predicted to reduce the differential pressure driven gas cross-permeation.

(C) The Author(s) 2016. Published by ECS. This is an open access article distributed under the terms of the Creative Commons Attribution 4.0 License (CC BY, http://creativecommons.org/licenses/by/4.0/), which permits unrestricted reuse of the work in any medium, provided the original work is properly cited. [DOI: 10.1149/2.1251613jes] All rights reserved.

(cc) BY
\end{abstract}

Manuscript submitted August 29, 2016; revised manuscript received September 23, 2016. Published October 21, 2016.

In a water electrolyzer, hydrogen is evolved at the cathode (the negative pole) while oxygen is evolved at the anode (the positive pole). When both electrodes are connected by an alkaline electrolyte, hydroxide ions must permeate from the cathode to the anode in order to bring about the electrochemical reactions at the electrodes. In such alkaline water electrolyzers, typically aqueous $\mathrm{KOH}$ electrolytes (which provide higher conductivity than other lyes ${ }^{1}$ ) and porous separators between both electrodes are used to provide the ionic conductivity between the electrodes and to separate the evolved gases., ${ }^{2,3}$ Alternatively, alkaline polymer electrolyte membranes can be used as the electrolyte. ${ }^{4-6}$ However, these membranes typically show low durability. ${ }^{7,8}$ The thickness of the separator, its ionic conductivity and its gas permeability constitute a decisive property for the efficiency of water electrolysis, as these properties determine the ohmic drop and cross-permeation of the produced gases. ${ }^{9-11}$ A recent comparison of acidic and alkaline water electrolysis showed, that the lower hydrogen and oxygen diffusivities in alkaline electrolytes than in acidic electrolytes may be a decisive advantage of alkaline electrolyzers. ${ }^{9}$ Higher pressures at the gas outlets during water electrolysis means reducing the mass fraction of water in the produced gases and thus lower thermoneutral voltages. ${ }^{9,12}$ In addition, applied pressures during water electrolysis enable efficient isothermal compression. ${ }^{13}$ However, higher pressures increase the amount of hydrogen and oxygen diffusing through the separator, ${ }^{9,10}$ so that porous separators that enable low gas crossover are required for efficient alkaline water electrolyzers.

Composite materials of Zirconium oxide (zirconia) and polysulfone are high-performing and stable separators for alkaline water electrolysis. ${ }^{14,15}$ This type of separator combines the flexibility of the polymer with the stiffness and wettability of the ceramic zirconia. ${ }^{16}$ Agfa provides a commercially available product of this type of separator, denoted as 'Zirfon PERL UTP 500'. In the datasheet of the manufacturer ${ }^{17}$ a thickness of approximately $500 \pm 50 \mu \mathrm{m}$, a porosity of $50 \pm 10 \%$ and pores of approximately $0.15 \pm 0.05 \mu \mathrm{m}$ diameter were reported. The manufacturing procedure and resulting physical properties, such as the wettability and porosity, are reported in the literature. ${ }^{14,16,18}$ However, a detailed quantitative study of the hydrogen diffusivity and electrolyte permeability of the Zirfon PERL separator or other types of separators has thus far not been presented in the literature, despite these properties have a decisive impact on the overall efficiency. ${ }^{9}$ Given this lack of knowledge, in this study these properties are characterized as a function of pressure, temperature and the composition of aqueous $\mathrm{KOH}$ filling. With reference to the measured diffusivities, the solubilities of hydrogen in $\mathrm{KOH}$ as a function

${ }^{c}$ Present address: Department of Interface Chemistry and Surface Engineering, MaxPlanck-Institut für Eisenforschung, 40237 Düsseldorf, Germany.

${ }^{\text {z} E-m a i l: ~ m . s c h a l e n b a c h @ m p i e . d e ~}$ of temperature are estimated. On the basis of these data, the amount of hydrogen that can be carried by the electrolyte permeation through the separator during water electrolysis are estimated. The hydrogen permeation fluxes through the separator during water electrolysis are estimated, providing the data to model the gas purities and efficiencies of electrolyzers. ${ }^{9}$ The results obtained for the hydrogen diffusivity are transferred to that of oxygen on the basis of the presented measurements and literature data. Finally, pore size reduction of the separator is suggested in order to reduce the differential pressure driven electrolyte permeation through the separator during water electrolysis.

\section{Methods}

In the following, the experimental setups used to measure the properties of Zirfon PERL samples are briefly described. The thickness of the examined samples was $d=462 \pm 10 \mu \mathrm{m}$.

Measurement of the hydrogen diffusivity.-Figure 1 shows the experimental setup employed to measure the hydrogen diffusivity in the Zirfon PERL separator with the electrochemical monitoring technique. A general description of the electrochemical monitoring technique to measure gas crossover and the physical theory of gas diffusion through aqueous solutions was provided in a previous study ${ }^{19}$

In the setup used, a sample of the Zirfon PERL separator was in direct contact with two electrolyte chambers that were filled with an aqueous $\mathrm{KOH}$ solution. As illustrated in Figure 1, hydrogen is bubbled through the electrolyte chamber left to the sample, which is in the following denoted as 'left electrolyte chamber'. In the left electrolyte chamber a Titanium plate of $8 \mathrm{~mm}$ thickness with a window of 10.9 $\mathrm{cm}^{2}$ was pressed onto the Zirfon PERL sample, which allowed the $\mathrm{KOH}$ solution to penetrate into the sample. In the electrolyte chamber on the other side of the Zirfon PERL sample (with reference to the illustration in Figure 1 denoted as the 'right electrolyte chamber'), a carbon fleece (Freudenberg, H23) that was coated via sputtering with 2 $\mathrm{mg}$ Platinum per $\mathrm{cm}^{2}$ of geometric area was used. This catalyst coated carbon fleece is in the following denoted as 'working electrode' and is filled with the same $\mathrm{KOH}$ electrolyte as the Zirfon PERL sample. At the platinum catalyst, hydrogen diffusing through the Zirfon PERL sample was electrochemically oxidized:

$$
\mathrm{H}_{2}+2 \mathrm{OH}^{-} \rightarrow 2 \mathrm{H}_{2} \mathrm{O}+2 e^{-}
$$

In order to enable this electrochemical oxidation reaction, the reverse reaction direction was provided at another electrode which is defined as the 'counter electrode'. This electrode is to identify with the Nickel plate of the cell that touched the electrolyte in the right chamber. Accordingly, the hydrogen at the working electrode is transported by an electrochemical pump to the counter electrode. Nitrogen 


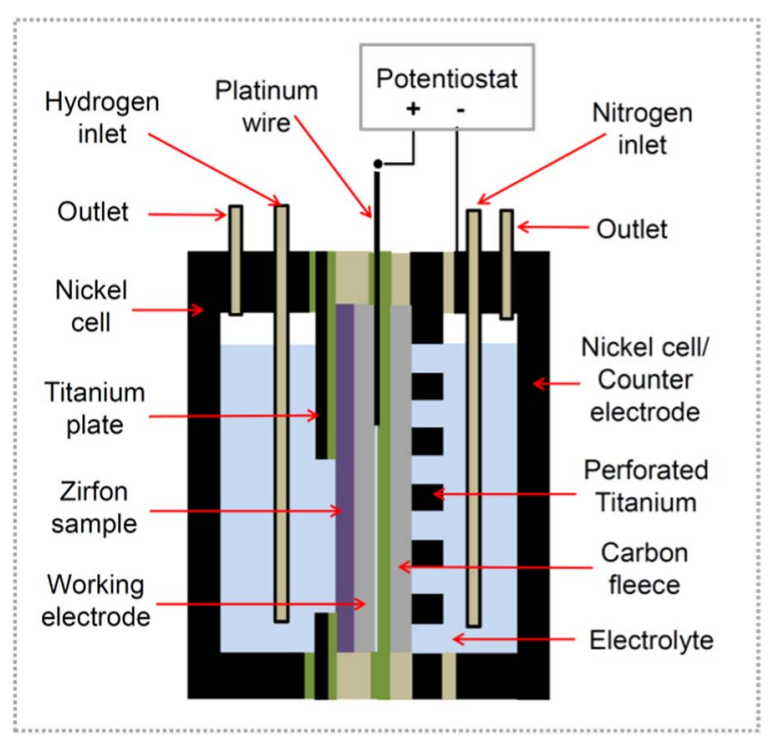

Figure 1. Schematic illustration of the setup used to measure the hydrogen diffusivity in the samples via the electrochemical monitoring technique. Black: Metals. Light blue: KOH electrolyte. Purple: Zirfon PERL separator. Gray: Carbon fleece. Ocher: PTFE sealing or tube. Green: Nafion NR321 membranes used for sealing.

is bubbled through the electrolyte in the right chamber and carries the hydrogen evolved at the counter electrode to the cell outlet. A constant voltage of $0.7 \mathrm{~V}$ is applied between the electrodes using a potentiostat (Biologic, SP-50), while the current density $j$ between both electrodes is monitored over time.

The working and counter electrode were separated by a Nafion NR321 (DuPont) membrane. This membrane was previously immersed in an aqueous solution of $\mathrm{KOH}$ in order to replace the protons of its functional groups by potassium cations. ${ }^{20,21}$ The KOH solution soaked by the Nafion membrane yield the conductivity to hydroxide ions ${ }^{22}$ which is required for their exchange between the electrodes. This hydroxide ions conduction between the electrodes is mandatory in order to enable the electrochemical half-reactions. As examined later, the Zirfon PERL separator is permeable to differential pressures, while differential pressures have a negligible influence on the permeation of water or gases through Nafion membranes. ${ }^{19}$ When different absolute pressures are applied to the left and right electrolyte chamber in this setup, the pressure difference thus drops at the Nafion membrane. As a result, the absolute pressures at both sides of the Zirfon PERL samples were equal. A perforated titanium plate and two carbon fleeces mechanically supported the Nafion membrane in order to withstand the applied differential pressures.

The electrochemical current between the working and counter electrode can be attributed to the conversion of hydrogen diffusing through the Zirfon PERL sample and parasitic contributions. These parasitic contributions arise from other sources than the electrochemical conversion of hydrogen that permeated through the separator and are considered later in detail. To distinguish between these different contributions to the current measured, a novel measurement procedure was developed, which will be described in the following.

Using Fick's law

$$
\Phi_{\mathrm{H}_{2}}^{\text {Fick }}=-D_{\mathrm{H}_{2}} \frac{\Delta c_{\mathrm{H}_{2}}}{d}
$$

the hydrogen mole flux normalized to the cell area (denoted as $\Phi_{\mathrm{H}_{2}}^{\text {Fick }}$ ) through a separator can be determined, while $D_{\mathrm{H}_{2}}$ describes the diffusion coefficient of hydrogen in this separator and $\Delta c_{\mathrm{H}_{2}}$ the concentration difference of dissolved hydrogen on both sides of this separator. By using Henry's law

$$
c_{\mathrm{H}_{2}}=S_{\mathrm{H}_{2}} p_{\mathrm{H}_{2}}
$$

the concentration of hydrogen in an electrolyte can be calculated as a function of the partial hydrogen pressure $p_{\mathrm{H}_{2}}$, while $S_{\mathrm{H}_{2}}$ denotes the hydrogen solubility. Using the latter equation, Fick's law can be expressed as a function of the partial pressure difference of hydrogen on both sides of the separator (denoted as $\Delta p_{\mathrm{H}_{2}}$ )

$$
\Phi_{\mathrm{H}_{2}}^{\text {Fick }}=-\varepsilon_{\mathrm{H}_{2}}^{\text {Fick }} \frac{\Delta p_{\mathrm{H}_{2}}}{d},
$$

while $\varepsilon_{\mathrm{H}_{2}}^{\text {Fick }}$ denotes the hydrogen diffusivity, which is often also denoted as permeability or Fick's permeability. In this study, the terminus diffusivity will be used for $\varepsilon_{\mathrm{H}_{2}}^{\text {Fick }}$ in order to avoid any possibility of confusion with the differential pressure permeability, which will be defined in the next section. When all the hydrogen that diffuses through the Zirfon PERL sample is electrochemically converted, $\Phi_{\mathrm{H}_{2}}^{\text {Fick }}$ can be related by Faraday's law to the current density $j$ between the electrodes

$$
\Phi_{\mathrm{H}_{2}}^{\text {Fick }}=\frac{j}{2 \mathrm{~F}},
$$

where $\mathrm{F}$ denotes the Faraday constant. If all hydrogen diffusing through the Zirfon PERL sample is electrochemically oxidized to water at the working electrode, the partial pressure at this electrode (and its interface to the separator) is negligible. In this case, the partial pressure difference $\Delta p_{\mathrm{H}_{2}}$ equals $p_{\mathrm{H}_{2}}$, which is defined as the partial hydrogen pressure in the left electrolyte chamber.

As mentioned previously, the measured current is also influenced by parasitic contributions. If $j_{\mathrm{H}_{2}}$ represents the electrochemical current caused by hydrogen conversion, the hydrogen diffusion through the Zirfon PERL sample can be related to the diffusivity by: ${ }^{19}$

$$
\varepsilon_{\mathrm{H}_{2}}^{\text {Fick }}=\frac{d j_{\mathrm{H}_{2}}}{2 \mathrm{~F} p_{\mathrm{H}_{2}}}
$$

The parasitic currents are estimated later to be independent of the partial pressure difference $\Delta p_{\mathrm{H}_{2}}$. In order to subtract these parasitic currents, the relative change of the measured current at two different partial hydrogen pressures (denoted by ' $p_{\mathrm{H}_{2}}^{\mathrm{a}}$.' and ' $\mathrm{p}_{\mathrm{H}_{2}}^{\mathrm{b}}$ ') in the left electrolyte chamber was considered, which cancels the parasitic contributions:

$$
\varepsilon_{\mathrm{H}_{2}}^{\text {Fick }}=\frac{d}{2 \mathrm{~F}} \frac{j^{\mathrm{a}}-j^{\mathrm{b}}}{p_{\mathrm{H}_{2}}^{\mathrm{a}}-p_{\mathrm{H}_{2}}^{\mathrm{b}}}
$$

In the experiments, the highest and lowest absolute pressures (5 bar and 1 bar) that were applicable to the left electrolyte chamber were used. The partial hydrogen pressure in the solution was calculated by

$$
p_{\mathrm{H}_{2}}=p-p_{\mathrm{wv}}
$$

where $p$ denotes the absolute pressure applied to the left electrolyte chamber and $p_{\mathrm{wv}}$ the partial pressure of saturated water vapor, which was determined with respect to the $\mathrm{KOH}$ concentration based on the data reported by Balej. ${ }^{23}$

The temperature of the cell was measured using Pt100 resistance thermometers (Electrotherm, Model K3-E-2LS-200). Heater cartridges (Horst $\mathrm{GmbH}$ ) embedded in the nickel plates of the cell were used to vary the cell temperature. Hydrogen and nitrogen were purged at rates of $1.5 \mathrm{ml}$ per minute through the left and right electrolyte chambers, respectively, set by mass flow controllers (Brooks, model 5850E). In PTFE tubes the gases were conducted to the bottom of the electrolyte chambers. The gas bubbles permeating from the bottom of the cell to the gas outlets led to turbulence of the electrolyte and thus an equal distribution of the dissolved gases in the electrolyte chambers. Inside the Zirfon PERL sample, the electrolyte in the pores is not swirled by the bubble movement in the electrolyte chamber. The absolute pressure of the left electrolyte chamber was set with a pressure controller (Brooks, model 5866) that was connected its outlet. Before the gas entered the pressure controller, it passed through a stainless steel condenser.

Measurement of electrolyte permeability.-To measure the electrolyte permeability of the Zirfon PERL samples, these were placed 


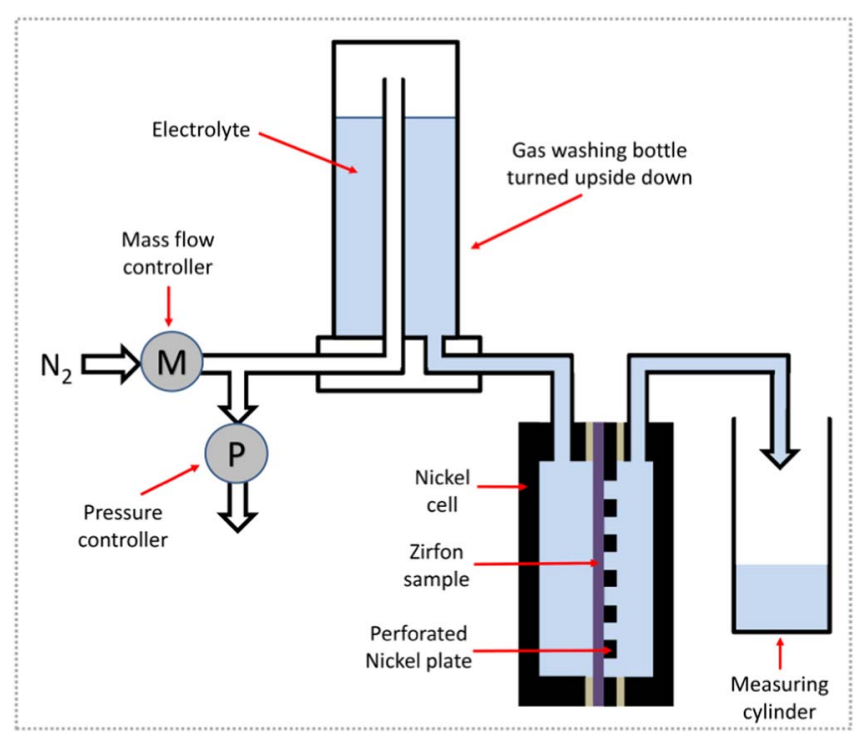

Figure 2. Schematic illustration of the setup to measure electrolyte permeation through a Zirfon PERL sample. The gas washing bottle (Bola, $500 \mathrm{ml}$ sample volume) and tubes (Bola, $4 \mathrm{~mm}$ inner diameter) were made of perfluorated plastic (PTFE or PFA) in order to resist the caustic $\mathrm{KOH}$ electrolytic solutions.

in a Nickel cell as illustrated in Figure 2. The cells were flooded with aqueous $\mathrm{KOH}$ solutions that also penetrated into the Zirfon PERL separator. On the left side of the Zirfon PERL separator in Figure 2, absolute pressures from 1.1 to 1.5 bar were applied, while the outlet of the other side was exposed to ambient pressure. The area of Zirfon PERL separator that was in contact with the electrolyte equaled $26 \mathrm{~cm}^{2}$, while the rest of the sample was compressed by the PTFE sealing and thereby tightened and sealed. In the compartment with ambient pressure, a perforated Nickel plate with an open area of $66 \%$ and round holes of $2 \mathrm{~mm}$ in diameter faced the sample in order to avoid the deformation of the sample through the applied differential pressures. The closed area of this perforated plate displays an infinite resistance to the electrolyte permeating through the Zirfon PERL separator. Accordingly, near the closed area of the perforated Nickel plate the electrolyte cannot permeate by the shortest way through the separator to the compartment with ambient pressure. Thus, the measured permeability of the separator is at maximum 33\% (the closed area of the Nickel plate) smaller than its real permeability, which has to be identified as a measurement error of the discussed setup.

As is displayed in Figure 2, a mass flow controller (Brooks, model $5850 \mathrm{E}$ ) and a pressure controller (Brooks, model 5866) for nitrogen gas were used to apply pressure to the cell. In a gas washing bottle turned upside down, the pressure of the gaseous phase was transferred to the electrolytic solution. The volume of pressurized electrolyte permeating in a defined time through the separator was measured as a function of the applied pressure and temperature using a measuring cylinder at the outlet of the cell. Based on the rates measured, the volumetric electrolyte flux normalized to the cell area (denoted as $\tilde{\Phi}_{\mathrm{el}}$ ) was calculated by:

$$
\tilde{\Phi}_{\mathrm{el}}=\frac{V}{t A}
$$

Using Darcy's law, the measured volumetric flux densities were correlated with the electrolyte permeability $K$ (in $\mathrm{cm}^{2}$ )

$$
\tilde{\Phi}_{\mathrm{el}}=-\frac{K}{\eta} \frac{\Delta p}{d},
$$

where $\Delta p$ denotes the absolute pressure difference between both sides of the Zirfon PERL separator and $\eta$ the viscosity of the electrolyte.

The measurement of the absolute pressure difference is affected by an offset, as described later in detail. In order to deduct the con- tributions of this offset, the derivative of $\tilde{\Phi}_{\mathrm{el}}$ in $\Delta \mathrm{p}$ was considered (on the basis of the latter equation) in order to determine the ratio of permeability to viscosity:

$$
\frac{K}{\eta}=-d \frac{\mathrm{d}\left(\tilde{\Phi}_{\mathrm{el}}\right)}{\mathrm{d}(\Delta \mathrm{p})}
$$

This derivate was determined by the slope of fitted lines to the measured $\tilde{\Phi}_{\mathrm{el}}$ as a function of $\Delta \mathrm{p}$ (graphed in Figure 7).

\section{Results and Discussion}

In the following, first measurements of the hydrogen diffusivity in the Zirfon PERL separator are presented. Second, based on the diffusivities measured and reported data on the diffusion coefficient, the solubility of hydrogen in $\mathrm{KOH}$ solutions is estimated as a function of temperature. Third, the measured electrolyte permeabilities of the Zirfon PERL separator are presented and their implications on the hydrogen crossover during water electrolysis are physically described. Fourth, it is discussed if bubbles can penetrate into the porous structure of the Zirfon PERL separator. Fifth, on the basis of the experimental data and the previous discussions, the hydrogen permeation flux through the Zirfon PERL separator during water electrolysis is discussed. Finally, the diffusivity, diffusion coefficient and solubility of hydrogen in relation to that of oxygen are estimated on the basis of the measured data and literature data.

Hydrogen diffusivity.-The diffusivity of hydrogen in the Zirfon PERL separator was characterized in 1, 10, 20, and $30 \mathrm{wt} \%$ aqueous $\mathrm{KOH}$ solutions using the setup illustrated in Figure 1. Based on the data reported by Gilliam et al., ${ }^{1}$ the compositions of these solutions correspond to $\mathrm{KOH}$ concentrations of $0.178,1.93$, 4.20, and 6.88 mole per liter.

Diffusing limiting current.-In the following, the current density between the working electrode and counter electrode that results from hydrogen diffusing through a Zirfon PERL sample is considered as a function of the applied voltage. In the case of the diffusion-limited current, an increase of the voltage does not increase the current density. If this condition is fulfilled, all the hydrogen that comes through the separator is electrochemically oxidized at the working electrode. Figure 3 shows the voltage-current characteristic between the working and counter electrode at room temperature with a $10 \mathrm{wt} \% \mathrm{KOH}$ electrolyte. Above $0.6 \mathrm{~V}$, the current density is independent of the voltage, which means that the diffusion-limited condition leads to a

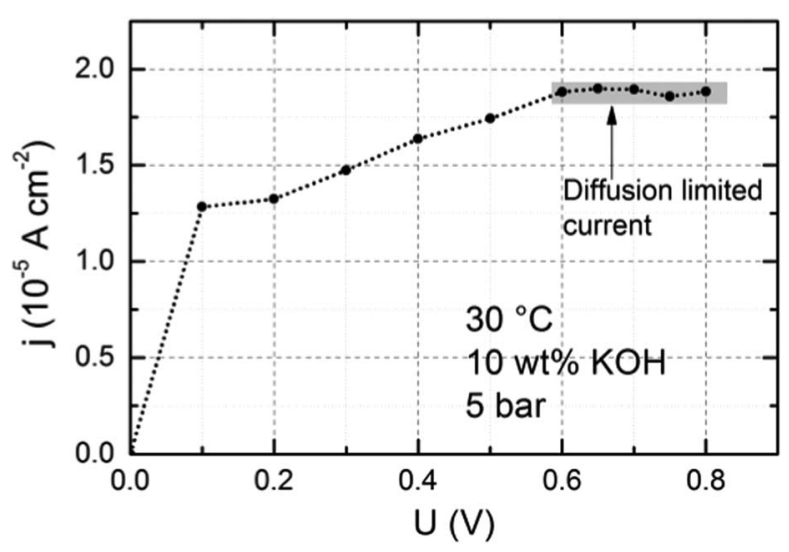

Figure 3. Current density that results from hydrogen diffusing through a Zirfon PERL sample as a function of the applied voltage between the electrodes. Measured at $30^{\circ} \mathrm{C}$ and an absolute pressure of $5 \mathrm{bar}$ in the left electrolyte chamber in $10 \mathrm{wt} \% \mathrm{KOH}$ electrolyte. The gray marked area indicates the saturation current density (diffusion-limited) where all hydrogen diffusing through the Zirfon PERL sample was electrochemically oxidized. 
saturated current density. Higher voltages were not used in order to avoid corrosion of the carbon-based working electrode.

In order to ensure that the diffusing limited current was reached for the measurements that are presented in the following sections, the current was measured at $0.65 \mathrm{~V}$ and $0.8 \mathrm{~V}$ at $25^{\circ} \mathrm{C}$ for a hydrogen pressure of 5 bara after the sample or electrolyte was changed. The deviations between the currents at $0.65 \mathrm{~V}$ and $0.8 \mathrm{~V}$ (after $1.5 \mathrm{~h}$ of measurement, respectively) for the same sample and electrolyte were smaller than $8 \%$ and therefore the diffusing limiting condition was verified. Towards higher temperatures the overpotentials for the hydrogen oxidation/reduction decrease so that the voltage at which the diffusing limited current is reached becomes smaller.

Influence of pressure.-Figure 4 shows the measured current densities as a function of the partial hydrogen pressures at $80^{\circ} \mathrm{C}$. Absolute pressures of 1,2, 3, 4, and 5 bar were applied to the left electrolyte chamber. Lines were fitted to the measured data in order to represent the linear relation between the current density and the partial hydrogen pressures that is obtained when Equations 4 and 5 are equated. The fitted lines should pass the origin, as Fick's law (Equation 4) says that the permeation flux density of hydrogen should equal zero when the partial pressure of hydrogen in the electrolyte is negligible. However, extrapolating the measured data to $p_{\mathrm{H}_{2}}=0$ leads to nonnegligible currents, which are defined in the following as parasitic currents. These parasitic currents may arise from oxygen or carbon dioxide impurities in the electrolyte introduced by the surrounding atmosphere or the nitrogen gas (purity of $99.999 \%$ ) that was purged through the right electrolyte chamber. Moreover, impurities in the $\mathrm{KOH}$ electrolyte, such as iron ions ${ }^{24}$ may be deposited at the electrodes and thus may have contributed to the measured current. Another source of parasitic currents may be the corrosion of carbon, platinum, and nickel used for the working and counter electrodes. Furthermore, hydrogen evolved at the counter electrode could diffuse back to the working electrode and thereby lead to a parasitic current. All these contributions are independent of the hydrogen pressure in the left electrolyte chamber. Accordingly, Equation 7 was used to correct the influence of the parasitic currents and to calculate the diffusivity on the basis of the measured current densities.

Toward higher concentrations of the $\mathrm{KOH}$ electrolyte the measured overall current decreased (as further described in the next section) so that the relative influence of the parasitic currents increased. At $1 \mathrm{wt} \%$ $\mathrm{KOH}$, the extrapolated parasitic current equals $10 \%$ of the measured current at 5 bar, while in the case of the $30 \mathrm{wt} \% \mathrm{KOH}$ solution, this contribution was $50 \%$.

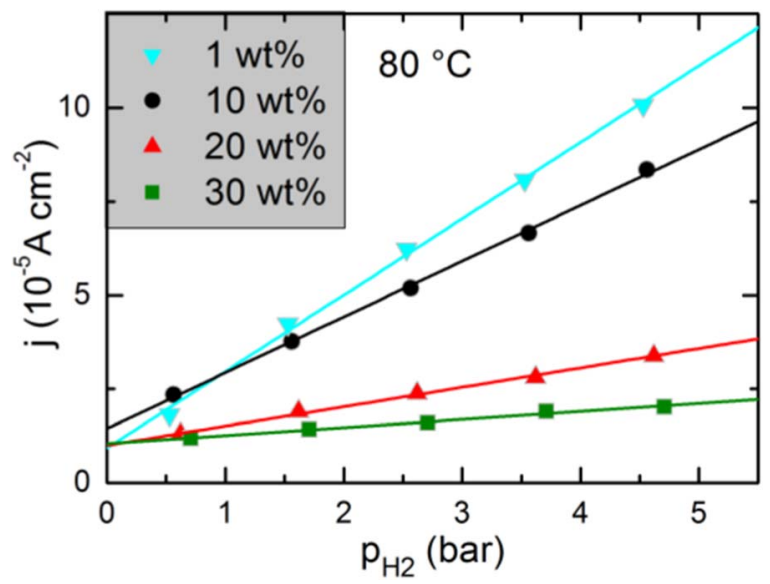

Figure 4. Current density between the working and counter electrode measured as a function of the partial hydrogen pressure in the left electrolyte chamber of Figure $1 \mathrm{~A}$. These measurements were conducted at $80^{\circ} \mathrm{C}$ and $\mathrm{KOH}$ fillings of between $1 \mathrm{wt} \%$ and $30 \mathrm{wt} \%$ as indicated by the color code.

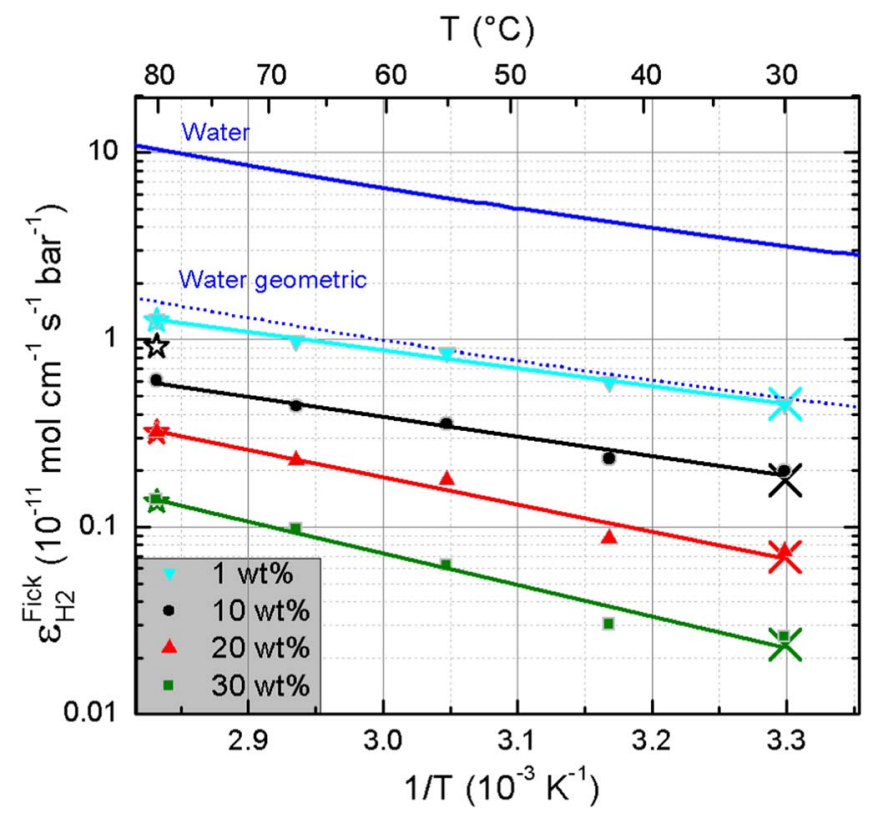

Figure 5. Hydrogen diffusivity as a function of the temperature in a modi-

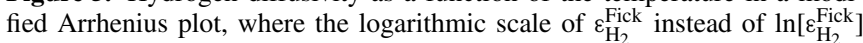
is graphed. Solid blue line: Hydrogen diffusivity in water calculated on the basis of literature data (see text for details) by Equation 13. Blue dotted line: Hydrogen diffusivity of water multiplied by the geometric factor $\zeta$. Colored crosses: Hydrogen diffusivity of the $\mathrm{KOH}$ solutions calculated from literature data multiplied by $\zeta$. Triangles, points and squares: Hydrogen diffusivities in the Zirfon PERL sample calculated from the measured currents using Equation 7. Colored lines: Fits to the diffusivities calculated from the measured currents. Stars: Hydrogen diffusivities (extracted from the data graphed in Figure 4) which were obtained with another Zirfon PERL sample than the othe data presented in this graph.

Influence of temperature and concentration.-Figure 5 shows the measured and calculated hydrogen diffusivities of the Zirfon PERL separator in a modified Arrhenius plot where the logarithmic scale of $\varepsilon_{\mathrm{H}_{2}}^{\text {Fick }}$ instead of the typically used $\ln \left[\varepsilon_{\mathrm{H}_{2}}^{\varepsilon^{\text {Fick }}}\right]$ was used. In this depiction, the Boltzmann distribution

$$
\varepsilon_{\mathrm{H}_{2}}^{\text {Fick }} \propto \exp \left[\frac{-E_{\mathrm{A}}}{\mathrm{k}_{\mathrm{B}} T}\right]
$$

linearizes, which describes the hydrogen diffusivity in aqueous solutions in good approximation. ${ }^{19,25}$ The hydrogen diffusivity can be calculated by: ${ }^{19}$

$$
\varepsilon_{\mathrm{H}_{2}}^{\text {Fick }}=D_{\mathrm{H}_{2}} S_{\mathrm{H}_{2}}
$$

The diffusivity of hydrogen in water is calculated on the basis of data reported in the literature ${ }^{\mathrm{d}}$. The diffusion coefficient of hydrogen in $\mathrm{KOH}$ is reported as a function of molarity and temperature, ${ }^{26}$ while data for the hydrogen solubility in $\mathrm{KOH}$ could only be found for $30^{\circ} \mathrm{C}^{27}$ Based on these reported values, the hydrogen diffusivity in $\mathrm{KOH}$ was calculated for $30^{\circ} \mathrm{C}$ for the different $\mathrm{KOH}$ concentrations used in this study.

The ceramic $\mathrm{ZrO}_{2}$ of the Zirfon PERL separator is impermeable to hydrogen, while the permeability of the polysulfone binder is assumed to be far smaller than that of the $\mathrm{KOH}$ solution. Accordingly, the tortuosity of the pores and the reduced volume fraction of the aqueous phase is expected to cause a lower overall hydrogen diffusivity in the Zirfon PERL separator than that in its $\mathrm{KOH}$ filling. The geometric factor $\zeta$ is defined here as the ratio of the hydrogen diffusivity of the Zirfon PERL separator divided by the diffusivity of the filling.

${ }^{\mathrm{d}}$ The hydrogen permeability of water is often calculated ${ }^{28}$ with reference to the diffusion coefficient reported by Wise et al. ${ }^{34}$ The hydrogen diffusivity of water calculated for Figure 5 was derived from Equation 13 with reference to the diffusion coefficient reported by Tham et al. ${ }^{26}$ which shows better agreement with values reported by other authors. ${ }^{35}$ 
Figure 5 shows hydrogen diffusivities calculated with Equation 7 from the measured currents. Moreover, this figure shows the diffusivities of hydrogen in $\mathrm{KOH}$ solutions (that were calculated on the basis of diffusion coefficients and solubilities reported in the literature ${ }^{26,28}$ ) multiplied by a geometric factor of $\zeta=0.159$. Using this value of $\zeta$, a good agreement of the diffusivities calculated from the literature data and those derived from measured currents resulted. The deviations between these values were below $6 \%$ with respect to the same $\mathrm{KOH}$ concentration. Accordingly, the value of $\zeta=0.159$ is a good approximation to describe the ratio of the diffusivity of hydrogen in the Zirfon PERL separator to that in its electrolyte filling.

The overall hydrogen diffusivity in a separator or membrane is a linear combination of the diffusivities in its aqueous and solid phase, as described by a resistor network model presented in the literature. ${ }^{25}$ Despite the diffusivity of the $\mathrm{KOH}$ filling is reduced by more than tenfold by an increase of the $\mathrm{KOH}$ content from $1 \mathrm{wt} \%$ to $30 \mathrm{wt} \%$, one value of the geometric factor was used to calculate the samples diffusivities. The only solution that allows a constant geometric factor that is independent of the electrolyte filling is a negligible diffusivity in the solid phase. Accordingly, the solid phase was estimated to not contribute to the hydrogen diffusivity in the Zirfon PERL separator in a measureable degree.

To evaluate the measurement precision, the hydrogen diffusivity of a second sample was examined (stars in Figure 5), which showed on average $8 \%$ higher diffusivity compared to that of the first sample. Table I displays the parameters for the Boltzmann distribution obtained from linear fits in Arrhenius plots $(\ln [\varepsilon]$ vs. $1 / T)$.

Hydrogen solubility in $\mathbf{K O H}$.-As discussed above, the diffusion coefficient of hydrogen in $\mathrm{KOH}$ solutions as a function of molarity and temperature is reported in the literature, ${ }^{26}$ while data for hydrogen solubility could only be found for $30^{\circ} \mathrm{C}$. The aim of the following deliberations is to extract the solubility of hydrogen in aqueous $\mathrm{KOH}$ solutions as a function of temperature and ion concentration on the basis of the measured hydrogen diffusivity graphed in Figure 6. In order to obtain the hydrogen diffusivity in the $\mathrm{KOH}$ solution inside the Zirfon PERL sample, the influence of its pore morphology on the diffusivity was eliminated by multiplying the measured values of the samples times the inverse of the estimated geometry factor of $1 / \xi=6.3$. Dividing the thus determined hydrogen diffusivity by the hydrogen diffusion coefficient reported by Tham et al. ${ }^{26}$ the hydrogen solubility was extracted using Equation 13. Figure 6 shows the hydrogen solubilities determined by this procedure.

The parameters describing the Boltzmann distributions of the hydrogen solubilities and diffusion coefficients are summarized in Table I. The solubility for hydrogen decreases toward higher concentrations of the $\mathrm{KOH}$ solution. Up to $10 \mathrm{wt} \%$ of the $\mathrm{KOH}$ solution, higher temperatures decrease the solubility (negative values of the heat of solution), while at higher concentrations the solubility decreases toward higher temperatures (positive values of heat of solution). Sim-

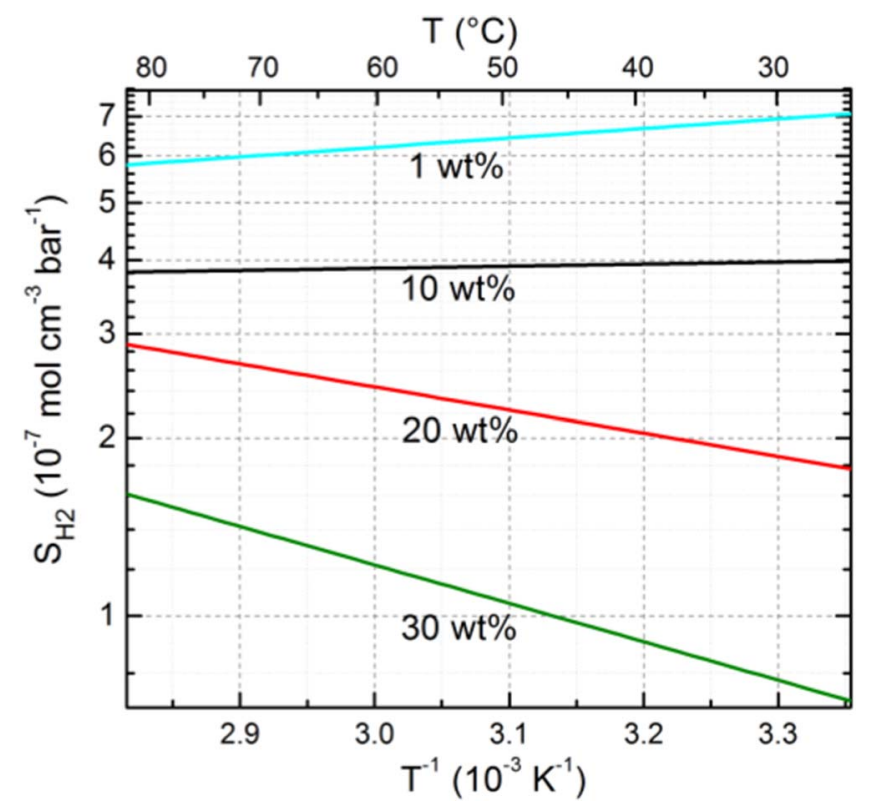

Figure 6. Hydrogen solubilities of $\mathrm{KOH}$ solutions in a modified Arrhenius plot calculated on the basis of the measured hydrogen diffusivities graphed in Figure 5 and the diffusion coefficients for hydrogen in $\mathrm{KOH}$ reported in the literature. ${ }^{26}$

ilar trends concerning the effects of temperature and molarity on the oxygen solubility in $\mathrm{KOH}$ solutions were reported in the literature. ${ }^{30}$

Electrolyte permeability.-When the absolute pressures on both sides of a porous separator are different, the electrolyte can be pushed through the separator. In order to minimize the resulting electrolyte cross-permeation through the separator during alkaline water electrolysis, balanced pressures are typically applied to the anodic and cathodic compartments. However, the values of the set pressures technically deviate from the desired set points, resulting in small pressure differences between the anode and cathode. The influence of these differential pressures on the electrolyte permeation through Zirfon PERL samples was examined for differential pressures up to 0.5 bar, as presented in the following. On the basis of this data, the hydrogen permeability during water electrolysis that is caused by the differential pressure-driven electrolyte permeability is quantified.

Pressure dependence.-Figure 7 shows the effect of differential pressures on the electrolyte permeation through the Zirfon PERL separator (in the form of the volumetric permeation flux density $\tilde{\Phi}_{\mathrm{el}}$ with reference to Equation 9) at $80^{\circ} \mathrm{C}$. The measured pressure difference

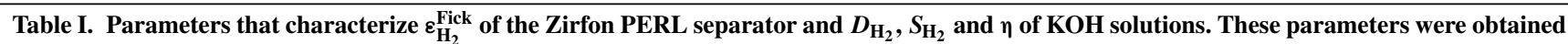
by linear fits of Equation 12 in Arrhenius plots. The parameter $E_{\mathrm{A}}$ describes the activation energies. In the case of solubility, $E_{\mathrm{A}}$ identifies with the heat of solution. Parameters of $\eta$ refer to Equation 14.

Prefactor

\begin{tabular}{|c|c|c|c|c|c|c|c|c|c|}
\hline \multirow[b]{2}{*}{ Property } & & \multirow[b]{2}{*}{ Units Prefactor } & \\
\hline & $1 \mathrm{wt} \%$ & $10 \mathrm{wt} \%$ & $20 \mathrm{wt} \%$ & $30 \mathrm{wt} \%$ & & $1 \mathrm{wt} \%$ & $10 \mathrm{wt} \%$ & $20 \mathrm{wt} \%$ & $30 \mathrm{wt} \%$ \\
\hline$\varepsilon_{\mathrm{H}_{2}}^{\text {Fick (a) }}$ & 6.9 & 5.3 & 0.40 & 0.82 & $10^{-9} \mathrm{~mol} \mathrm{~cm}^{-1} \mathrm{~s}^{-1} \mathrm{bar}^{-1}$ & 3.06 & 3.33 & 4.60 & 5.36 \\
\hline$D_{\mathrm{H}_{2}}^{\mathrm{H}_{2}}$ (b) & 2.1 & 1.1 & 0.70 & 0.47 & $10^{-1} \mathrm{~cm}^{2} \mathrm{~s}^{-1}$ & 3.57 & 3.44 & 3.36 & 3.29 \\
\hline$S_{\mathrm{H}_{2}}$ (c) & 20 & 30 & 3.6 & 0.11 & $10^{-6} \mathrm{~mol} \mathrm{~cm}^{-3} \mathrm{bar}^{-1}$ & -0.51 & -0.11 & 1.24 & 2.07 \\
\hline$\eta^{(\mathrm{d})}$ & 2.2 & 4.4 & 5.6 & 5.9 & $10^{-3}$ bar s & 2.48 & 2.28 & 2.29 & 2.44 \\
\hline
\end{tabular}

${ }^{a}$ Fit to the data based on the measurements graphed in Figure 5.

${ }^{\mathrm{b}}$ Fit to the data reported by Tham et al. ${ }^{26}$

${ }^{\mathrm{c}}$ Obtained by Equation 13 and by deducting the contributions of the geometric factor to $\varepsilon_{\mathrm{H}_{2}}^{\mathrm{Fick}}$.

${ }^{\mathrm{d}}$ Fit to the data reported in the literature. ${ }^{29}$ 


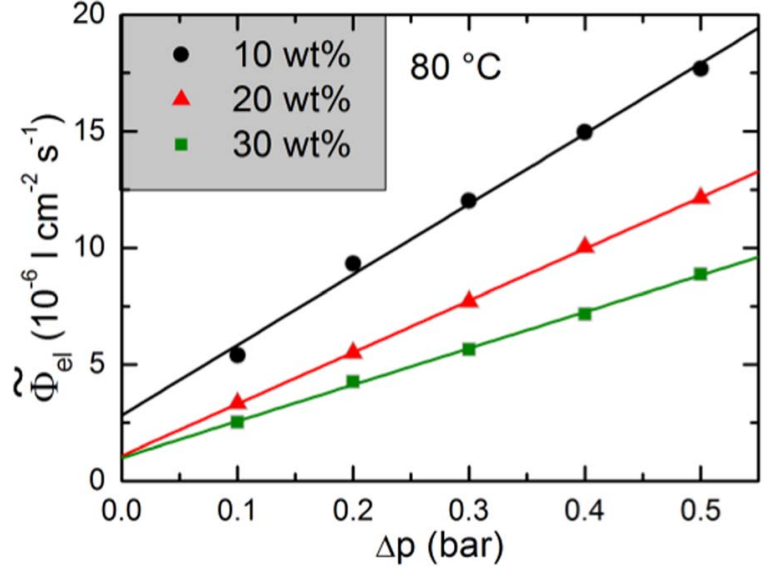

Figure 7. Volumetric permeation flux density $\tilde{\Phi}_{\mathrm{el}}$ of the electrolyte through a Zirfon PERL sample as a function of the absolute pressure difference at a cell temperature of $80^{\circ} \mathrm{C}$.

at the Zirfon PERL separator is influenced by the hydrostatic pressure (height differences of the electrolyte containers), capillary pressures of the electrolyte in the tubes and the bubble pressure at the electrolyte outlet. These parasitic contributions to the measured pressure led to non-negligible flux densities when extrapolating the measured volumetric flux densities $\tilde{\Phi}_{\mathrm{el}}$ to $\Delta p=0$. In order to correct this offset, the slope of the fitted lines to the data will be used to calculate the electrolyte's permeability via Equation 11.

The viscosity of the aqueous $\mathrm{KOH}$ solution increases with the amount of $\mathrm{KOH}$ dissolved (as characterized by the parameters stated in Table I). This larger viscosity decreases electrolyte cross-permeation, as described by Darcy's law in the form of Equation 10 .

Estimation of the electrolyte permeability.-As discussed in the last section, the derivative of the permeation flux in the differential pressure was used to determine the electrolyte permeability. Correspondingly, the slopes of the fitted lines plotted in Figure 7 were related to the ratio of electrolyte permeability $K$ to viscosity $\eta$ using Equation 11. In order to determine the electrolyte permeability $K$, data for the viscosity of potassium hydroxide solutions reported in the literature ${ }^{29}$ was fitted to the Arrhenius-Andrade equation:

$$
\eta=\eta_{0} \exp \left[\frac{E_{\eta}}{\mathrm{k}_{\mathrm{B}} T}\right]
$$

The fit parameters thereby determined are summarized in Table I.

Figure 8 shows the permeability $K$ as a function of the temperature calculated on the basis of Equation 11, volumetric fluxes measured and the viscosity calculated from literature data. The effect of the molarity and temperature on the volumetric fluxes is described by the viscosity. Accordingly, from a theoretical point of view, the permeability should be a constant. The mean permeability in the total temperature range equals $K \approx 0.075 \mathrm{~cm}^{2}$. The deviations from this mean value were up to $30 \%$ while the measurement error of the volumetric fluxes and pressures was less than $10 \%$. The deviations from the mean permeability were non-reproducible (see for comparison the relative change of the permeabilities of the two different samples measured). The non-reproducible deviations may be a result of a changing morphology of the samples during the measurements which can be forced by the applied pressure differences. The deviations of up to $30 \%$ from the mean must be considered as an uncertainty of the determined values. The statistical scattering of the measurement data does not allow to draw conclusions regarding trends of the permeability as a function of temperature or molarity.

Hydrogen convection caused by electrolyte cross-permeation.When the electrolyte permeates through the Zirfon PERL separator during alkaline water electrolysis, dissolved hydrogen or oxy-

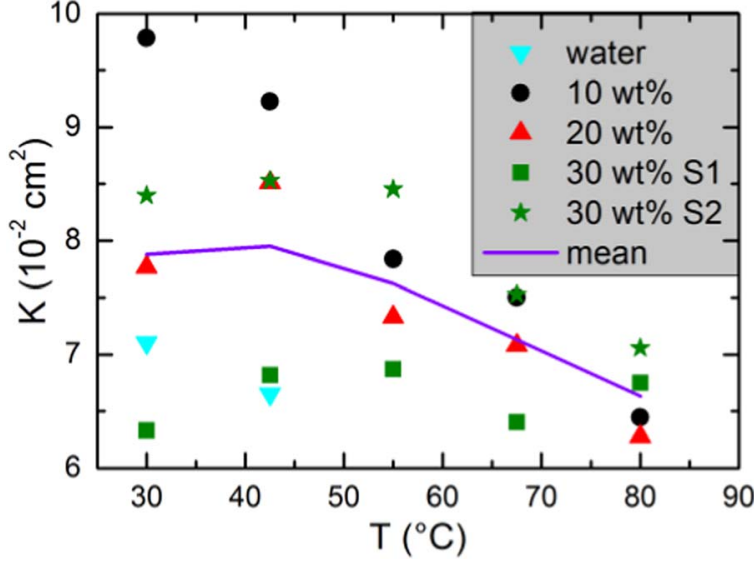

Figure 8. Electrolyte permeability $K$ of Zirfon PERL samples calculated by Equation 11 and the measured volumetric permeation flux densities as a function of temperature for different KOH solutions. S1: Sample 1. S2: Sample 2. Purple line: Mean of all the measurements. The rest of the color and symbol codes are the same as those in Figure 5

gen are also carried along. In the following, this convection of dissolved hydrogen by the differential pressure-driven electrolyte crosspermeation is quantified for the case of water electrolysis at higher cathodic than anodic absolute pressures. In the case of higher anodic than cathodic pressures, anodic oxygen can be carried along by the electrolyte that permeates to the cathode. The oxygen crosspermeation will be considered later in more detail.

In Equation 10, the ratio of $K$ to $\eta$ describes the volumetric permeability of the Zirfon PERL separator in the units of $\mathrm{ml} \mathrm{cm}^{-1} \mathrm{~s}^{-1} \mathrm{bar}^{-1}$. By multiplying this ratio with $c_{\mathrm{H}_{2}}$ and by using Henry's law (Equation 3), the hydrogen permeability $\varepsilon_{\mathrm{H}_{2}}^{\text {Darcy }}$ (in mol cm $\mathrm{cm}^{-1} \mathrm{~s}^{-1} \mathrm{bar}^{-1}$ ) caused by the differential pressure-driven electrolyte permeation is here defined as:

$$
\varepsilon_{\mathrm{H}_{2}}^{\text {Darcy }}=\frac{K}{\eta} S_{\mathrm{H}_{2}} p_{\mathrm{H}_{2}}^{\text {cat }}
$$

The driving force for this permeability is the absolute pressure difference $\Delta p$, while the amount of hydrogen carried along with the electrolyte depends on the partial hydrogen pressure $p_{\mathrm{H}_{2}}^{\text {cat }}$ at the cathode. Hence, based on Henry's law (Equation 3), $p_{\mathrm{H}_{2}}^{\text {cat }}$ has a linear influence on $\varepsilon_{\mathrm{H}_{2}}^{\text {Darcy }}$. As described by Darcy's law, the molar permeation flux density $\Phi_{\mathrm{H}_{2}}^{\text {Dary }}$ of hydrogen through the separator caused by differential pressures can be determined by:

$$
\Phi_{\mathrm{H}_{2}}^{\text {Darcy }}=-\varepsilon_{\mathrm{H}_{2}}^{\text {Darcy }} \frac{\Delta p}{d}
$$

Figure 9 shows $\varepsilon_{\mathrm{H}_{2}}^{\text {Dary }}$ for $p_{\mathrm{H}_{2}}^{\text {cat }}=1$ bar as a function of temperature for the different molarities of the $\mathrm{KOH}$ electrolyte considered. Higher $\mathrm{KOH}$ contents decrease the hydrogen solubility and increase viscosity. Both effects reduce $\varepsilon_{\mathrm{H}_{2}}^{\text {Darcy }}$.

Permeation of bubbles through Zirfon.-In the previous section, the influence of the electrolyte permeation through a separator during water electrolysis on the convection of dissolved hydrogen was discussed. The following deliberations are addressed to the question if the electrolyte can also carry gaseous hydrogen in the form of bubbles through the Zirfon PERL separator. The hydrogen concentration $c_{\mathrm{H}_{2}}$ in the gaseous phase can be approximated by the ideal gas law $\left(c_{\mathrm{H}_{2}}^{\text {gas }} \approx \frac{p_{\mathrm{H}_{2}}}{\mathrm{R} T}\right)$, while the hydrogen concentration $c_{\mathrm{H}_{2}}^{\text {dis }}$ of dissolved hydrogen can be approximated by Henry's law. Accordingly, the ratio of both concentrations can be calculated as follows:

$$
\frac{c_{\mathrm{H}_{2}}^{\text {gas }}}{c_{\mathrm{H}_{2}}^{\mathrm{dis}}}=\frac{1}{\mathrm{R} T S_{\mathrm{H}_{2}}}
$$




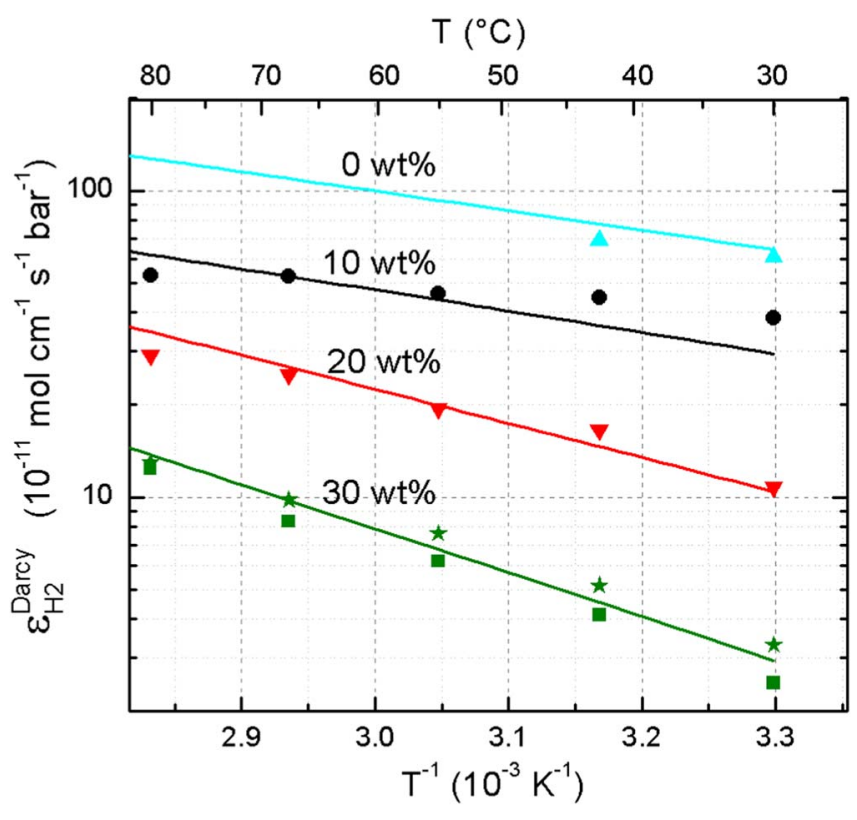

Figure 9. Modified Arrhenius plot of the hydrogen permeability caused by the differential pressure driven permeation for $p_{\mathrm{H}_{2}}^{\text {cat }}=1$ bar. The same color code as that in Figure 5 is used.

In the case of $30 \mathrm{wt} \% \mathrm{KOH}$, the values of this ratio range from 220 to 520 in the thus far considered temperature range. Hence, when gas bubbles that penetrate into the pores are carried along with a differential pressure-forced electrolyte flux these dramatically increase the crossover. With reference to the same volume pushed by differential pressures through the separator, more gaseous hydrogen than dissolved hydrogen in the aqueous phase is transported. Moreover, the friction of the gas transport is smaller than that of the electrolyte transport, which means an increase of the permeabilities.

Janssen et al. ${ }^{31}$ report that the average diameter of microbubbles during the hydrogen and oxygen evolution in aqueous $\mathrm{KOH}$ solutions is higher than $4.8 \mu \mathrm{m}$ at atmospheric pressure. As the pores of Zirfon PERL are with $0.15 \pm 0.05 \mu \mathrm{m}$ more than one order of magnitude smaller than the evolved gas bubbles, these can probably not penetrate into the pores at atmospheric pressures. However, higher pressures decrease the bubble diameter and could lead to bubble penetration into the separator. The capillary pressure of the electrolyte inside the wetted pores may display a repulsive force that could avoid the penetration of gas bubbles.

Gas bubbles with larger diameters than that of the pores are assumed to be not able to penetrate into the pores of the Zirfon PERL separator. However, this assumption is stated here with caution, as the minimum bubble diameter as a function of the pressure is unknown. By measuring hydrogen content in the anodic oxygen, the overall cross-permeation flux of hydrogen can be estimated..$^{10}$ If such measurements reveal that the hydrogen permeation flux is higher than that approximated, this difference could be related to the convection of bubbles during the cross-permeation of the electrolyte.

Hydrogen crossover during water electrolysis.-The aim of the following section is to elucidate the influence of the driving forces of differential concentrations and pressures on the overall hydrogen cross-permeation through the Zirfon PERL separator during alkaline water electrolysis. The interactions of both mechanisms are neglected and the influence of the bubble permeation through the Zirfon PERL separator is assumed to be negligible. Figure 10 graphs the influence of the electrolyte composition and temperature on the ratio of the hydrogen permeability to the hydrogen diffusivity for $p_{\mathrm{H}_{2}}^{\text {cat }}=1$ bar.

In order to explain why the ratio in Figure 10 is nearly independent of the composition of the $\mathrm{KOH}$ solution, the theory of diffusion must

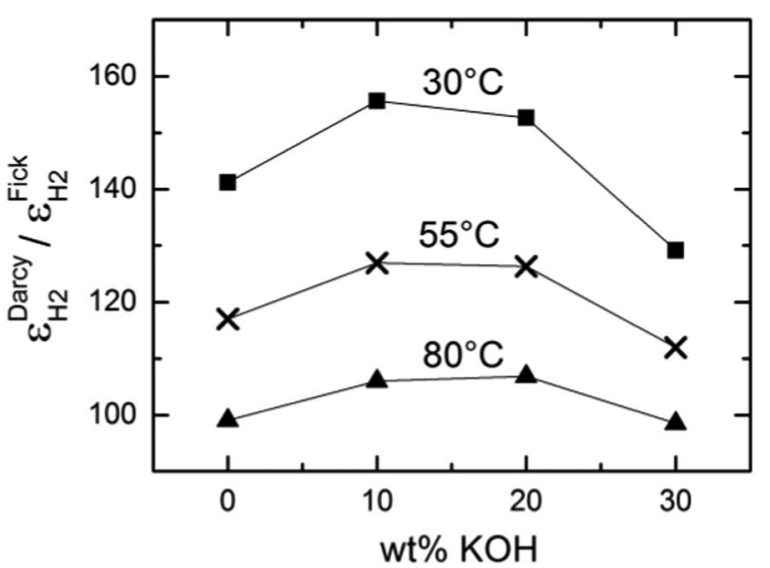

Figure 10. Ratio of the hydrogen permeability driven by the electrolyte permeation for $p_{\mathrm{H}_{2}}^{\text {cat }}=1$ bar to the hydrogen diffusivity as a function of the $\mathrm{KOH}$ composition.

be considered in more detail. On the basis of Equation 13 and 15, the ratio of the hydrogen permeability to the hydrogen diffusivity can be calculated to:

$$
\frac{\varepsilon_{\mathrm{H}_{2}}^{\text {Darcy }}}{\varepsilon_{\mathrm{H}_{2}}^{\text {Fick }}}=\frac{K}{D \eta} p_{\mathrm{H}_{2}}^{\text {cat }}
$$

As permeability and diffusivity are proportional to hydrogen solubility, their ratio is independent of it. Einstein described the relation between the mobility $\mu$ and diffusion coefficient by: ${ }^{32}$

$$
D=\mathrm{k}_{\mathrm{B}} T \mu
$$

The mobility $\mu$ is related to the viscosity $\eta$ by Stokes' law

$$
\mu=\frac{1}{\beta \eta},
$$

where $\beta$ denotes a geometrical factor with the dimension of a length, which equals $\beta=6 \pi r$ in the case of spherical diffusing particles with a radius of $r$. Based on the latter two equations, the product of the diffusion coefficient and viscosity can be derived to be independent of the electrolyte composition:

$$
D \eta=\frac{\mathrm{k}_{\mathrm{B}} T}{\beta}
$$

Thus, with reference to Equation 18 , the ratio of $\varepsilon_{\mathrm{H}_{2}}^{\text {Darcy }}$ to $\varepsilon_{\mathrm{H}_{2}}^{\text {Fick }}$ is also expected to be independent of the electrolyte composition. The change of the ratio of $\varepsilon_{\mathrm{H}_{2}}^{\text {Darcy }}$ to $\varepsilon_{\mathrm{H}_{2}}^{\text {Fick }}$ with the temperature graphed in Figure 10 is approximately twice as large as that predicted by the combination of the latter equation and Equation 18. Deviations from Equation 21 were reported for aqueous $\mathrm{KOH}$ solutions, ${ }^{33}$ which might be the source of the different values of the theoretical prediction and those measured.

On the basis of Equations 4, 15 and 16, the relation of the molar hydrogen permeation flux densities caused by the two different driving forces can be calculated to:

$$
\frac{\Phi_{\mathrm{H}_{2}}^{\text {Darcy }}}{\Phi_{\mathrm{H}_{2}}^{\text {Fick }}}=\frac{K}{D \eta} \Delta p
$$

As $\frac{K}{D \eta}$ is only slightly influenced by the temperature (see discussion above) and nearly independent of the electrolyte composition, the ratio of the permeation fluxes depends primarily on the absolute pressure difference $\Delta p$. Using the values derived above (for a $30 \mathrm{wt} \% \mathrm{KOH}$ solution and a temperature of $80^{\circ} \mathrm{C}$ ), the latter relation can be estimated to

$$
\frac{\Phi_{\mathrm{H}_{2}}^{\text {Darcy }}}{\Phi_{\mathrm{H}_{2}}^{\text {Fick }}} \approx \frac{\Delta p}{0.01}
$$




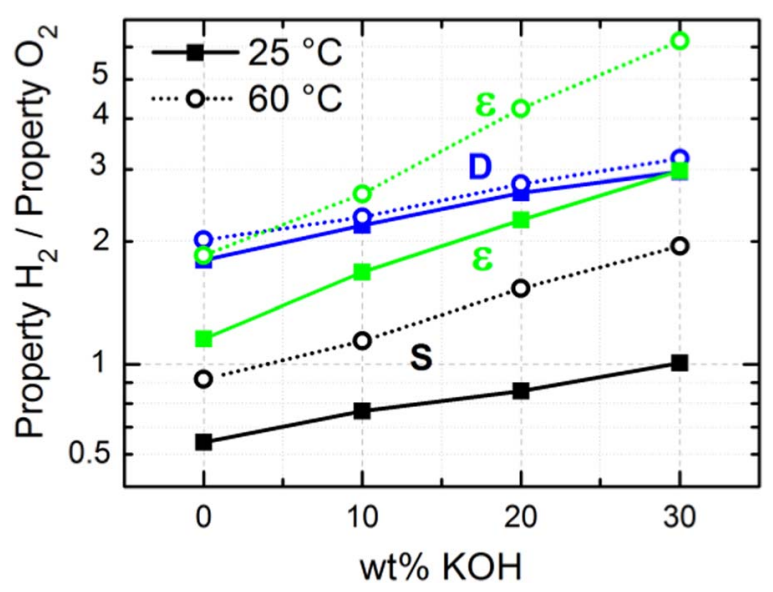

Figure 11. Ratios of the solubility (black), diffusion coefficient (blue) and diffusivity (green, calculated by Equation 13) of hydrogen in $\mathrm{KOH}$ solutions to those of oxygen as a function of the $\mathrm{KOH}$ composition (based on the data in Table I and literature data for the solubility ${ }^{30}$ and diffusion coefficient ${ }^{26}$ of oxygen). Squares and solid lines: $25^{\circ} \mathrm{C}$. Open circles and dotted line: $60^{\circ} \mathrm{C}$.

while only small changes have to be expected for other temperatures.

The latter relation is in the following exemplified for two different examples, where different pressures are assumed. In both cases the pressure control of the anodic and cathodic compartment is assumed to be as precise as $1 \%$ of the absolute values of the applied pressures (while only higher cathodic than anodic pressure are discussed). With reference to this precision, atmospheric operation pressures mean absolute pressure differences of at maximum 0.01 bar. In this case, the diffusion and differential pressure driven permeation fluxes are approximately equal. Using the same assumptions but an operation pressure of 50 bar the absolute pressure difference equals 0.5 bar. Accordingly, the hydrogen permeation flux driven by differential pressures can estimated to be approximately 50 times larger than that driven by the diffusion. Using the assumptions above, the hydrogen cross-permeation flux density scales quadratic with the applied pressure. Accordingly, at a operation pressure of 50 bar the hydrogen cross-permeation flux density is 2500 times higher than that at 1 bar. In summary, the pressure balance of the anodic and cathodic compartment in alkaline electrolyzers with Zirfon PERL separators is especially toward high pressures of significant importance to achieve high gas purities.

Oxygen diffusivities and solubilities.-The aim of this section is to estimate the oxygen diffusivity in $\mathrm{KOH}$ solutions. Tham et al. ${ }^{26}$ reported the diffusion coefficients of hydrogen and oxygen in $\mathrm{KOH}$ as a function of molarity and temperature. The solubility of oxygen in aqueous solutions of $\mathrm{KOH}$ was reported by Davis et al. ${ }^{30}$ for $25^{\circ} \mathrm{C}$ and $60^{\circ} \mathrm{C}$ as a function of the molarity. On the basis of these literature data and the hydrogen solubilities graphed in Figure 6, the ratios of the solubilities, diffusion coefficients and diffusivities of hydrogen to those of oxygen in $\mathrm{KOH}$ was graphed Figure 11. The relative changes of the hydrogen and oxygen diffusion coefficients with the $\mathrm{KOH}$ composition and temperature are nearly equal, as the diffusion coefficient depends primarily on the viscosity (Equation 19). At $60^{\circ} \mathrm{C}$ the hydrogen diffusivity in $\mathrm{KOH}$ was estimated to be six times higher than that for oxygen.

Improved separators for alkaline water electrolysis.-If separators with smaller pores diameter can be manufactured an enhanced repulsion of bubbles results. Moreover, smaller pore diameters would also increase the friction of electrolyte permeation (Hagen-Poiseuille equation). Thus, the differential pressure-forced electrolyte permeability is expected to decrease when separators with smaller pore diameters can be produced.

\section{Conclusions}

In this study, the hydrogen diffusivity and electrolyte permeability of the Zirfon PERL separator with regard to its application in alkaline water electrolyzers was characterized. The hydrogen diffusivity of aqueous $\mathrm{KOH}$ solutions calculated from literature data was approximately 6.3 times larger than that of the same solutions in the Zirfon PERL separator, which was ascribed to the influence of the pore geometry. On the basis of the measurements it was concluded that the influence of the solid phase on the overall diffusivity of hydrogen in the Zirfon PERL separator is negligible. Besides the hydrogen diffusivity, the differential pressure driven electrolyte cross-permeation of the Zirfon PERL separator was examined. When the absolute pressure of the cathodic compartment during alkaline water electrolysis is 0.01 bar higher than that of the anodic compartment, the contributions of the hydrogen cross-permeation forced by the differential pressures and concentration differences were estimated to be equal. If Zirfontype diaphragms with smaller pore diameters can be manufactured, the differential pressure forced permeability can be reduced.

\section{Acknowledgment}

This research was supported by the German Federal Ministry of Economic Affairs and Energy under grant No. 03ESP106A.

\section{List of Symbols}

A

$c$

D

d

$E_{A}$

F

$j$

$j_{\mathrm{H}_{2}}$

K

$k_{\mathrm{B}}$

$p$

$\Delta p$

$p_{\text {gas }}$
$p_{\mathrm{H}_{2}}^{\text {cat }}$

S

$T$

$\mathrm{wt} \%$

$\beta$ $\varepsilon_{\mathrm{H}_{2}}^{\text {Darcy }}$ $\mathrm{H}_{2}$

$\varepsilon_{\mathrm{H}_{2}}^{\text {Fick }}$

$\eta$

$\eta_{0}$

$\eta_{0}$

$\mu$

$\underset{\tilde{\Phi}_{\mathrm{el}}}{\phi}$

$\Phi_{\mathrm{H}_{2}}^{\text {Darcy }}$

$\zeta$

Active area, $\mathrm{cm}^{2}$

Concentration, $\mathrm{mol} \mathrm{l}^{-1}$

Thickness, $\mathrm{m}$

Activation energy, J

Current density, $\mathrm{A} \mathrm{cm}^{-2}$ $\mathrm{A} \mathrm{cm}^{-2}$

Absolute pressure, bar trolysis, bar

Temperature, $\mathrm{K}$

\section{Greek} mol cm ${ }^{-1} \mathrm{~s}^{-1}$ bar $^{-1}$ mol cm ${ }^{-1} \mathrm{~s}^{-1}$ bar $^{-1}$

Viscosity, bar s

Mobility, $\mathrm{s} \mathrm{kg}^{-1}$

Porosity, dimensionless $\mathrm{ml} \mathrm{cm}{ }^{-2} \mathrm{~s}^{-1}$ sures, $\mathrm{mol} \mathrm{cm} \mathrm{cm}^{-2} \mathrm{~s}^{-1}$ ferences, $\mathrm{mol} \mathrm{cm} \mathrm{cm}^{-2} \mathrm{~s}^{-1}$
$\Phi_{\mathrm{H}_{2}}^{\text {Fick }} \quad \mathrm{H}_{2}$ permeation flux density driven by concentration dif-

Diffusion coefficient, $\mathrm{cm}^{2} \mathrm{~s}^{-1}$

Faraday constant, $96485 \mathrm{C} \mathrm{mol}^{-1}$

Current density caused by hydrogen cross-diffusion,

Permeability of the electrolyte, $\mathrm{cm}^{2}$

Boltzmann constant, $1.381 \times 10^{-23} \mathrm{~J} \mathrm{~K}^{-1}$

Absolute pressure difference, bar

Partial pressure of a gas, bar

Cathodic partial hydrogen pressure during water elec-

Solubility, mol cm ${ }^{-3} \mathrm{bar}^{-1}$

Weight percent, dimensionless

Geometry factor of diffusing gas molecules, $\mathrm{m}$

Hydrogen permeability driven by differential pressures,

Hydrogen diffusivity (or Fick's permeability),

Prefactor viscosity, bar s $\mathrm{K}^{-1}$

Volumetric electrolyte permeation flux density,

$\mathrm{H}_{2}$ permeation flux density driven by differential pres-

Geometric factor, dimensionless 


\section{Subscripts}

$\begin{array}{ll}\mathrm{H}_{2} & \text { Hydrogen } \\ \text { wv } & \text { Water vapor } \\ \mathrm{O}_{2} & \text { Oxygen }\end{array}$

\section{Superscripts}

a, b Letters representing two different pressures

dis Dissolved hydrogen in the liquid phase

gas Gaseous phase

\section{References}

1. R. Gilliam, J. Graydon, D. Kirk, and S. Thorpe, Int. J. Hydrogen Energy, 32, 359 (2007).

2. R. Renaud and R. Leroy, Int. J. Hydrogen Energy, 7, 155 (1982).

3. H. Wendt and H. Hofmann, J. Appl. Electrochem., 19, 605 (1989).

4. M. Faraj et al., Int. J. Hydrogen Energy, 37, 14992 (2012).

5. Y. Leng et al., J. Am. Chem. Soc., 134, 9054 (2012).

6. L. Xiao et al., Energy Environ. Sci., 5, 7869 (2012).

7. C. C. Pavel et al., Angew. Chemie, 126, 1402 (2014).

8. G. Merle, M. Wessling, and K. Nijmeijer, J. Memb. Sci., 377, 1 (2011).

9. M. Schalenbach et al., J. Electrochem. Soc., 163, F3197 (2016).

10. M. Schalenbach, M. Carmo, D. L. Fritz, J. Mergel, and D. Stolten, Int. J. Hydrogen Energy, 38, 14921 (2013).

11. M. Schalenbach, Int. J. Hydrogen Energy, 41, 729 (2015).

12. R. L. LeRoy, C. T. Bowen, and D. J. LeRoy, J. Electrochem. Soc., 127, 1954 (1980).

13. B. Bensmann, R. Hanke-Rauschenbach, I. K. Peña Arias, and K. Sundmacher, Electrochim. Acta, 110, 570 (2013).
14. L. Xu, W. Li, Y. You, S. Zhang, and Y. Zhao, Front. Chem. Sci. Eng., 7, 154 (2013).

15. P. Vermeiren, W. Adriansens, J. Moreels, and R. Leysen, Int. J. Hydrogen Energy, 23, 321 (1998).

16. P. Vermeiren, R. Leysen, H. Beckers, J. Moreels, and A. Claes, J Porous Matter, 15, 259 (2008).

17. AGFA, Zirfon Perl UTP 500. Separator membrane for alkaline water electrolysis. Product information, p. 1, (2016).

18. P. Aerts et al., J. Phys. Chem. B, 110, 7425 (2006).

19. M. Schalenbach et al., Phys. Chem. C, 119, 25145 (2015)

20. A. Steck and H. Yeager, Anal. Chem., 52, 1215 (1980).

21. H. Yeager and A. Steck, J. Electrochem. Soc., 128, 1880 (1982).

22. R. S. Yeo, J. McBreen, G. Kissel, F. Kulesa, and S. Srinivasan, J. Appl. Electrochem., 10, $741(1980)$.

23. J. Balej, Int. J. Hydrogen Energy, 10, 233 (1985).

24. L. Trotochaud, S. L. Young, J. K. Ranney, and S. W. Boettcher, J. Am. Chem. Soc., 136, 6744 (2014).

25. M. Schalenbach, M. Hoeh, J. Gostick, W. Lueke, and D. Stolten, Phys. Chem. C, 119, 25156 (2015)

26. M. K. Tham, R. D. Walker, and K. E. Gubbins, J. Phys. Chem., 74, 1747 (1970).

27. P. Ruetschi and R. F. Amlie, J. Phys. Chem., 70, 718 (1966).

28. H. Ito, T. Maeda, A. Nakano, and H. Takenaka, Int. J. Hydrogen Energy, 36, 10527 (2011).

29. I. Zaytsev and G. Aseyev, Properties of Aqueous Solutions of Electrolytes, CRC Press, Boca Raton, (1992).

30. R. E. Davis, G. L. Horvath, and C. W. Tobias, Electrochim. Acta, 12, 287 (1967).

31. L. Janssen, C. Sillen, E. Barendrecht, and S. Van Stralen, Electrochem. Acta, 29, 633 (1984).

32. A. Einstein, Ann. Phys., 332, 549 (1905).

33. K. E. Gubbins and R. D. J. Walker, J. Electrochem. Soc., 112, 469 (1965).

34. D. Wise and G. Houghton, Chem. Engeneering Sci., 21, 999 (1966).

35. D. M. Himmelblau, Chem. Rev, 64, 527 (1964). 